\title{
Retorika Dakwah Ustadz Haikal Hassan
}

\author{
Meri Astuti $^{{ }^{*}}$, Atjep Mukhlis ${ }^{1}$, Asep Shodiqin ${ }^{2}$ \\ 1,2Jurusan Komunikasi dan Penyiaran Islam, Fakultas Dakwah dan Komunikasi, UIN Sunan \\ Gunung Djati, Bandung \\ *Email : meriastuti48@gmail.com
}

\begin{abstract}
ABSTRAK
Dakwah mengandung pengertian fokus pada penekanan proses pemberian bantuan, penyebaran pesan, pengorganisasian, dan penyebaran sumber daya manusia. Era modern ini berdakwah bukan hanya melalui ceramah dari mimbar saja, melainkan media dakwah sekarang sudah sangat luas, dengan teknologi yang semakin canggih berdakwah. Saat menyampaikan ceramahnya Ustadz Haikal Hassan selalu terlihat bersemangat dan menunjukan ekspresi wajah yang sesuai dengan setiap apa yang di sampaikan. Tulisan ini bertujuan untuk mengetahui bagaimana ethos phatos dan logos ustadz haikal hassan dengan dalam penelitian ini adalah teori Aristoteles menjelaskan tentang bahwa prinsip retorika terdiri dari ethos,phatos dan logos. Juga di dukung dengan teori Harold Lasswell menjelaskan who say what in channel to whom with what effect.menggunakan metode analisis isi, bertujan untuk menggunakan pesan atau isi yang tersirat dan tersurat dalam sebuah dokumentasi. Hasil dari penelitian ini membuktikan bahwa prinsip retorika yaitu ethos phatos dan logos ethos dimiliki oleh Ustadz Haikal Hassan.

Kata kunci : Haikal Hassan, Retorika, Media Sosial
\end{abstract}

\begin{abstract}
Da'wah contains a meaning that focuses on emphasizing the process of providing assistance, disseminating messages, organizing, and distributing human resources. This modern era of preaching is not only through lectures from the pulpit, but the media of preaching is now very broad, with increasingly sophisticated technology of preaching. When delivering his lecture, Ustadz. Haikal Hassan always looks enthusiastic and shows facial expressions that match what is said. This paper aims to find out how the ethos of phatos and logos ustadz haikeal hassan with in this study Aristotle's theory explains that the principle of rhetoric consists of ethos, phatos and logos. Also supported by Harold Lasswell's theory explains who say what in the channel to whom with what effect. Using the content analysis method, it is raining to use the message or the content that is implied and express in a documentation. The results of this
\end{abstract}


M.Astuti, A. Mukhlis, A. Shodiqin

study prove that the rhetoric principle of ethos phatos and logos ethos is owned by Ustadz. Haikal Hassan

Keywords: Haikal Hassan, Rhetoric, Social Media

\section{PENDAHULUAN}

Dakwah mengandung pengertian fokus pada penekanan proses pemberian bantuan, penyebaran pesan, pengorganisasian, dan penyebaran sumber daya manusia. Sistem dalam menjelaskan kebenaran, kebaikan, petunjuk ajaran, menganalisis tantangan, problem kebatilan, urgensi pengalaman aspek pesan, dan profesionalisme. Pada intinya dakwah merupakan perilaku muslim dalam menjalankan Islam sebagai agama dakwah. (Hajiri, 2015:17)

Dakwah sendiri memiliki degradasi untuk menunjang keberhasilannya, yang tergantung terhadap beberapa komponen yang sangat berpengaruh yakni da'i sebagai orang yang menyampaikan pesan terhadap mad'u (komunikator), kemudian mad'u sebagai orang yang menerima pesan dari da'i (komunikan), materi dakwah sebagai pesan yang akan disampaikan oleh da’i. Media dakwah yang dijadikan sarana untuk menyampaikan pesan dakwahnya.

Secara bahasa tabligh berasal dari akar kata b-l-gh : (ballaghayuballighu, tablighan). Yang berarti menyampaikan atau melaporkan, dalam arti menyampaikan sesuau kepada orang lain, yang dalam hal ini adalah tabligh berkaitan erat dengan menyampaikan hal hal baik yang mengajak untuk beriman kepada Allah swt. Dalam bahasa Arab seseorang yang menyampaikan tabligh di sebut dengan mubligh.

Dalam pandangan Muhammad A'la Thanvi, seorang leksikograf abad ke 18 di India, membahas tabligh sebagai sebuah istilah dalam ilmu retorika, dalam konsep Islam tabligh merupakan salah satu perintah yang di bebankan kepada para utusa Allah. (Aliyudin \& Enjang, 2009:53)

Dari segi metode, tabligh di bagi menjadi dua macam yaitu melalui lisan (khitobab) dan tulisan (khitabah), kemudian yang akan penulis bahas adalah khitobah. Khitobah dari segi bahasa berasal dari kata : (khatabah, yakhtuba, khuthbah, atau khitabatan). Berarti :berkutbah, berpidato, meminang, melamar, bercakap-cakap, mengirim surat. Kemudian secara bahasa juga khitabah diartikan sebagai pengajaran, pembicaraan, dan nasihat. Khitobah bukan hanya sekedar pidato biasa melainkan memiliki pesan yang memiliki nilai Islami yang harus di sampaikan pada khalayak.

Retorika adalah suatu istilah yang secara tradisional yang didasarkan pada suatu bahasa sebagai seni, yang didasarkan pada suatu pengetahuan yang tersusun dengan baik. Retorika juga diartikan sebagai prinsip-prinsip mengenai komposisi pidato yang persuasif dan efektif, maupun keterampilan yang harus di miliki oleh seorang orator (ahli pidato) (Keraf,2010 : 1) 
Retorika tidak bisa dipisahkan dari para mubaligh dalam menyiarkan Agama Islam kepada khalayak umum, yang dengan retorika ini bisa menjadi salah satu penunjang keberhasilan oleh seorang da $i$ dalam menyampaikan pesan bernilai Islam dengan berbagi seni retorika yang bisa membuat mad'u tertarik.

Era modern ini berdakwah bukan hanya melalui ceramah dari mimbar saja, melainkan media dakwah sekarang sudah sangat luas, dengan teknologi yang semakin canggih berdakwah bisa menjadi mudah dan praktis. Media dakwah di era globalisasi ini berkembang sangat pesat yaitu melalui, majalah, radio, televisi dan youtube yang sekarang sedang marak di akses dan banyak digunakan oleh khalayak adalah media sosial.

Media sosial menurut Meike dan Young mengartikan kata media sosial sebagai konvergasi anatara komunikasi personal dalam arti saling berbagi di antara individu (to be shared one to one. (Nasrullah, 2017 : 14)

Instagram merupakan media yang sangat populer sekarang, banyak orang yang mengaksesnya, karena bisa di akses dimana pun dan kapanpun, dan hampir semua orang baik di desa atau pun kota dan banyak di seluruh dunia juga yang menggunakan Instagram.

Salah satu ustadz yang berdakwah mengguankan Instagram adalah Ustadz Haikla Hassan memiliki nama lengkap Ahmad Haikal bin Hassan bin Umar bin Salim bin Ali bin Syehk Abdullah Baros lahir di Jakarta 22 Oktober 1970. Beliau adalah seorang konsultan perusahaan namun sekarang beliu lebih fokus untuk berdakwah, cara berdakwahnya berbeda dengan ustadz ustadz lainnya, beliau berdakwah dengan cara yang tegas dan prontal namun terlihat lucu yang selalu bisa mengundang gelak tawa para jama'ahnya dengan selalu memakai kecamata hitam andalannya saat bercanda membuat Ustadz Haikal Hassan memiliki daya tarik para jama’ahnya. Selain berdakwah secara langsung Ustadz Haikal Hassan juga berdakwah melalui media sosial yaitu Instagram.

Saat menyampaikan ceramahnya Ustadz Haikal Hassan selalu terlihat bersemangat dan menunjukan ekspresi wajah yang sesuai dengan setiap apa yang di sampaikan. Banyak materi ceramahnya yang selalu di sambungkan dengan sejarah Islam karena beliau sudah di sebuat juga sebagi pakar sejarah Islam, namun selain semua itu Ustadz Haikal Hassan dalam ceramahnya juga memberikan solusi konkrit di serta dengan logika dan permasalahan zaman sekarang.

Seperti pada penelitian Skripsi sebelumnya yang berjudul Retrorika Tabligh Buya Yahya (Studi Deskriptif di Al- Bahjah TV Online). Siti Rosa Farihatul 'ain. Penelitian ini berkaitan dengan penggunaan retorika. Adapun penelitiannya menggunakan metode deskriptif.

Penelitian ini memilii beberapa kesamaan dengan dengan beberapa skripsi sebelumnya. Adapun Nama Instagram Ustadz Haikal Hassan adalah 
@haikalhassan_quote yang berisi tentang ceramah ceramah beliau, baik itu melalui tulisan atau pun video, selain kegiatan ceramahnya, Ustadz Haikal Hassan yang di panggil dengan sebutan Babeh lahir di Jakarta, di dalam Instagramnya sering berbagi tentang kehidupannya sehari hari serta opini opini yang prontal. Dalam video-videonya di Instgram sangat lah menarik dimana cara penyampian beliau yang ceplas ceplos dan selalu membuat suasana menjadi seru namun pesannya tetap tersampaikan.

Dari latar belakang masalah tersebut dapat dirumuskan beberapa masalah dengan fokus penelitian: Bagaimana etos ustadz Haikal Hasan dalam instagram (a)haikalhasan_quote?, Bagaimana phatos yang digunakan oleh Ustadz Haikal Hassan dalam instagram @haikalhassan_quote?, Bagaimana logos yang digunakan oleh Ustadz Haikal Hassan dalam instagram@haikalhassan_quote?

Dalam penelitian ini menggunakan Metode penelitian mengenai retrorika dakwah Ustadz Haikal Hassan, untuk menghasilkan data objektif dalam penelitian ini maka, penulis menggunakan metode kualitatif deskriptif. Penelitian kualitatif lebih menghendaki arah bimbingan penyusunan teori substantif yang berasal dari data dan menganalisis peristiwa, yang merupakan sikap atau kegiatan sosial baik secara indvidu atau pun kelompok. (Syaodih, 2009 : 53).

\section{LANDASAN TEORITIS}

Teori yang digunakan secara kerangka secara teorikal, konseptual dan operasional. Secara teoritikal penelitian ini menggunakan teori komunikasi yang dikemukankan Lasswell yakni who says what in which Channel to whom with what effect. Model teori Laswell yang di kemukankan pada tahun 1948 menggambarkan bahwa proses komunikasi di bebankan pada masyarakat berserta fungsinya.

Retorika adalah sebuah seni berbicara yang persusif dan efektif yang harus di miliki seorang orator atau da'i yang mengatur tentang kata kata dan bahasa agar saat berbicara terdapat kesan baik pada mad'u. (Maarif, 2015 : 2)

Secara terminilogi, retorika adalah seni berbicara di depan khalayk umum atau berpidato menggunakan tata bahasa yang baik, benar, lancar, yang bertujuan untuk mempengarui para pendengarnya. Retorika menerangkan sebuah kaidah-kaidah landasan dari sebuah tulisan bersifat prosa yang akan membentuk pidato, orasi, atau pun ceramah yang akhirnya harus mempengaruhi perasaan dan sikap orang. (Muhtadi, 2013 :17).

Istilah retorika dalam pembendaharaan kata bahasa inggris adalah rhetoric yang artinya kepandaian berbicara atau berpidato. Retorika juga merupakan sebuah seni yang menggunakan kata-kata yang mengesankan baik dari lisan maupun tulisan, ataupun berbicara di depan khalayak umum dengan menggunakan pertunjukan atau rekaan. (Suhandang, 2009:25). 
Dakwah secara etimologi memiliki arti sebagai ajakan, seruan, dan panggilan. Yang berasal dari bahasa Arab yaitu da'wah,da'a, yad'u. Sedangkan secara terminologi tentang dakwah ini memiliki banyak pendapat. Menurut para ahli pada intinya dari semua pendapat para ahli dakwah adalah sebuah proses untuk mendorong, mendukung dan bahkan mengajarkan kepada hal yang lebih baik dari sebelumnya, yaitu Hijrah. (Tajiri, 2015 : 15)

Unsur unsur dalam kegiatan dakwah, mubaligh disebut sebagai seorang komunikator, maudhu ( pesan), Ushlub ( metode), Wasilah (media) dan mad'u (objek). Yang dengan itu mubaligh sebagai komunikator yang akan menyampaikan pesan harus memiliki keterampilan retorika yang baik, agar pesan yang disampaikan dapat di terima dengan baik pada objek yang di tuju. Secara operasional.

Dakwah di kelompokan dalam 3 kategori yang pertama. dakwah bi $\mathrm{Al}$ Lisan, yaitu dakwah yang dilaksanakan melalui lisan, yang dilakukan antara lain dengan ceramah-ceramah,khutbah, diskusi, nasihat, dan lain lain. Dakwah billisan yang mengajak untuk melakukan perintah Allah Swt dan menjauhi laranganNya yang di lakukan dalam bentuk Al-Hikmah, Al-Mau'idza Al-Hasanah, dan Al-Mujadalah.

Kata media lebih dikenal sebagai alat dalam melakukan komunikasi, adapun proses terjadinya suatu komunikasi ditentukan oleh tiga bentuk, yaitu: objek, organ dan yang terakhir adalah medium. Sedangkan yang dimaksud dengan sosial yaitu kata sosial dalam media sosial secara teori semestinya di dekati oleh ranah sosiologi.

Adapun pengertian media sosial setelah mengetahui bagaimana pengetahuan dasar tentang media dan juga sosial, juga diperlukan pendekatan dari teori-teori sosial untuk memperjelas apa yang apa yang membedakan antara antara media sosial dan media lainnya.

Instragram merupakan media sosial tempat berbagi foto atau video yang paling populer saat ini. Pada awalnya instagram hanya tersedia di aplikasi IOS/iphone/ipad tapi saat inisudah tersedia untuk berbagai OS yang lain.

Media sosial adalah sebuah medai online dengan para penggunanya bisa dengan mudah untuk ikut berpartisipasi, berbagi dan menciptakan isi meliputi blog jejaring sosial forum dan didunia virtual. Media sosial dapat membuat manusia berkomuikasi satu sama lainsekalipun jarak diantara mereka sangat jauh. Falam pencapaian tujuan komunikasi dakwah, maka seorang penyampai dakwah dituntut untuk mampu melakukan inovasi-inovasi dalam mendesain pola dakwah kepada masyarakat atau mad'u, serta seorang dai dituntut untuk cerdas dalam memilih dan memilah media yang akan digunakan dalam melakukan kegiatan dakwah. 
Laswell mengemukaakan tiga fungsi komunikasi, yaitu : pertama, pengawassan lingkungan, yang mengingatkan anggota anggota masyarakat akan bahaya dan peluang dalam lingkungan, kedua, korelasi berbagi bagian terpisah dalam masyarakat yang memproses lingkungan, dan yang ketiga, transmisi warisan sosial dari suatu generasi ke generasi lainnya. (Mulyana, 2016:69).

Selain teorikal menurut Laswel peneliti juga menggunakan teoritikal menurut Aristotles pakar sejarah retorika yang berasal dari Yunani yang memang banyak menyinggung tentang retrorika sehingga beliau di juluki sebagai bapa retorika. Menurut Aristotles retorika tidak lain dari pada" kemapuan untuk menentukan, dalam kejadian tertentu dan situasi tertentu, metode persuasi yang ada". Yang dalam tahap itu juga pembicara merumuskan tujuan dan mengumpulkan bahan (argumen) yang sesuai dengan kebutuhan khalayak. (Rakhmat, 2012:7).

Peneliti menggunakan dua teori yaitu teori dari Harold Lasswell dan teori dari Aristoteles yang akan di jadikan acuan bagi peneliti agar lebih jelas dan fokus. Harold Lasswel menjelaskan bahwa komunikasi itu akan menjawab pertanyaan : Who say wabt in channel to whom with what effect?

Maksud dari unsur yang di katakan oleh Harold Lasswell adalah who adalah untuk memancing pertanyaan mengenai pesan, says what yaitu bahan yang di gunakan untuk analisis isi, in which channel saluruan atau media komunikasi yang di gunakan, kemudian to whom yang di kaitkan dengan khalayak atau kepada siapa, kemudian with what effect berkaitan dengan apa akibat pesan yang di sampaikan oleh pembicara dapat menimbulkan perubahan pada diri audiens.

Bapak retorika yang terkenal adalah Aristotles, Menurut Aristotles retorika adalah seni berbicara di depan umum, menurutnya ada tiga bagian inti dalam retorika : Pertama, Ethos (ethical), Yaitu sebuah karakter pembicara yang dapat dilihat dari cara ia berkomuikasi, untuk menuntukan pada khlayak bahwa ia adalah seorang yang memiliki kepribadian yang terpercaya dan pengetahuan yang luas. Ethos adalah potensi persuasif pada karakter dan kredibilitas personal pembicara. (Maarif, 2015 : 9). Kedua, Pathos (emotional), yaitu perasaan emosional khalayak yang dapat dipahami dengan sebuah pendekatan " psikilogi massa" untuk mengetahui perasaan pendengar. Phatos ini menurut kamus Inggris yang di susun oleh Liddell dan Scott yaitu pengalaman baik dan buruk, kondisi tertentu, serta emosi jiwa. Menurut Aristoteles phatos merupakan sebuah pergerakan (kinesis) yang dalam bentuk kekuatan pendorong suatu perubahan (dynamei on), kualitas gerak perubahan (alloiosis), maupun dari gerak perubahan (paschein). Selain pendapat ini menurut Aristoteles phatos merupakan sebah perasaan atau jiwa. Dalam bukunya phatos merupakan sebuah persuasi pada emosi pendengar, yang artinya seorang komunikator harus bisa mempengaruhi emosi komunikan. 
Ketiga, Logos (logical) yaitu pemilihan kata, kaliamt, atau emosi ungkapan oleh pembicara dengan baik dan benar yang memiliki bukti yang konkrit atas apa yang di sampaikannya pada khalayak. Menurut Aristoteles bahwa logos mengacu pada argumentasi dan logika dalam retrorika. Jadi logos adalah berkaitan dengan pembicaraan yang akan di sampaikan oleh orator yang bertujan untuk membujuk audiens.

\section{HASIL DAN PEMBAHASAN}

Perjalanan dakwah nya tidak mulus, banyak yang menyebutnya radikal karena dalam ceramahnya sering membawa unsur pemerintahan. Dakwahnya di medai sosial pun tidak selalu mulus, semua akun medai sosoailnya yaitu twitter, dan Instagram pernah di bajak oleh orang yang tidak di kenal. Ustadz Haikal Hassan pun mendapatkan penghargaan sebagai Man of The year.

Setelah peneliti meneliti video-videoUstadz Haikal Hassandi Instagram, dakwah atau ceramah Ustadz Haikal Hassansangat menarik dari pemilihan kata dan intonasi. Gaya bahasanya yang khas menggunakan bahasa Betawi serta ceplas-ceplos selalu berhasil membuat para jamaah tertawa.Berbicara tentang gaya bahasa takan lepas dari komunikasi dan retorika yang di gunakan di dalamnya. Karena retorika adalah sebuah seni untuk berbicara agar lebih terstuktur dan pesan yang di samapaikan bisa di mengerti.Retorika merupakan salah satu disiplin ilmu yang membahas tentang kemampuan berbicara sesorang di depan khalayak dengan tata cara yang sistematis dan logis sehingga pesan yang di sampaikan oleh pembicara atau orator dapat tersampaikan kepada khalayak sebagai pendengar .

\section{Hasil dan Pembahasan}

Dakwahnya di medai sosial pun tidak selalu mulus, semua akun medai sosoailnya yaitu twitter, dan Instagram pernah di bajak oleh orang yang tidak di kenal. Ustadz Haikal Hassan pun mendapatkan penghargaan sebagai Man of The year. Setelah peneliti meneliti video-video Ustadz Haikal Hassandi Instagram, dakwah atau ceramah Ustadz Haikal Hassansangat menarik dari pemilihan kata dan intonasi. Gaya bahasanya yang khas menggunakan bahasa Betawi serta ceplas-ceplos selalu berhasil membuat para jamaah tertawa.Berbicara tentang gaya bahasa takan lepas dari komunikasi dan retorika yang di gunakan di dalamnya.

"wah ngeledek, kalau kalimatnya Allah solawat kepada anbiya, lu bener, karena anbiya bentuk jamak dari nabi, Allah manggil Musa, ya Musa, ya Isa, ya Ibrahim, ya Nuh, Allah panggil semua, tapi kalau Allah panggil Nabi Muhammad, ya ayyunna nabi, wahai nabi, ya ayyuhal rasul, wahai rasul, halus" 


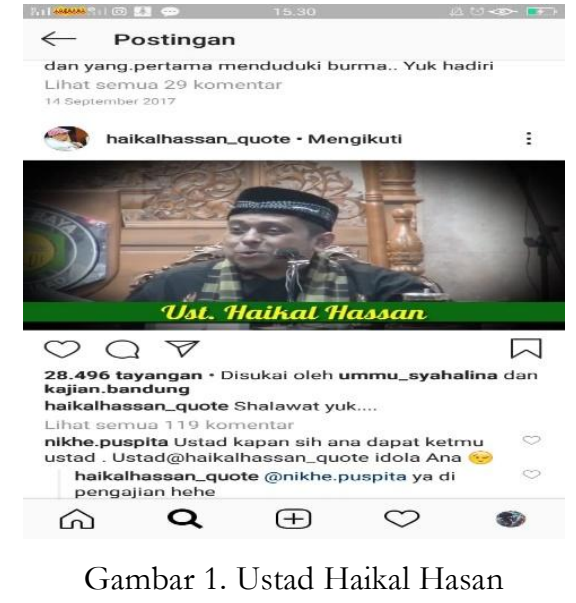

Dari semua ekspresi di atas menunukan babeh saat cermah memiliki ekpresi yang berbeda beda sesuai dengan apa yang dia sampaikan . ekpresi itu ketika babeh mengatakan " elu jangan so tau, shalwat itu memang untuk nabi, nabi di sini maksudnya Rasulullah ".

Arete di sini bisa di artikan berupa inteletualistas dan karakter. Untuk intelktualitas dapat di raih dengan melalui sebuah pendidikan sedangkan karater bisa di raih melalui sebuah kebiasaan . dalam hal ini Ustadz Haikal Hassan pun dapat dikatakan sudah termasuk kedalam, dalam pendidikan Ustadz Haikal Hassan sudah menempuh hingga S3 bahkan sekarang sedang menempuh S3 kembali. Kemudian dari segi karkater dan kebiasaan dalam berbicara dan berdakwah, Ustadz Haikal Hassan sudah berdakwah dari dulu, di awali dari mengajar ngaji anak anak dan para remaja hingga bisa terkenal seperti sekrng yang ceramahnya sudah di mana mana. Dan bisa di lihat dari ceramhnya di atas bahwa Ustadz Haikal Hassan memiliki ilmu, karena beliau hafal hadits nabi dalam ceramahnya. Peneliti mun menyimpulkan bahwa Ustadz Haikal Hassan memiliki arete dalam dirinya.

eunoia adalah sebuah niat baik pada semua orang yang tanpa di dasari oleh kepentingan pribadi. Dalam hal ini peneliti menilai Ustadz Haikal Hassan sudah memilikinya di lihat dari ceramah yang di jelaskannya,bahwa dalam ceramahnya Ustadz Haikal Hassan mengingtkan para jamaahnya untuk sadar agar bisa memilih pemimpin yang muslim, namun hal itu di lakukan karena rasa peduli beliau untuk umat, tanpa da kepentingan pribadi. Hal ini membuktikan bahwa Ustadz Haikal Hassan memilik eunoia. Kemudian pada saat peneliti melakukan penelitian langsung ke Jakarta dan bertemu dengan Rani salah satu tim management Ustadz Haikal Hassan menuturkan bahwa, Ustadz Haikal Hassan mulai semangat berdakwah dan bangkit lagi hingga dikenal seperti sekarang adalah karena Jakarta di pimpin oleh non muslim, hal itu membuat Ustadz Haikal Hassan semangat untuk berdakwah lebih giat lagi.Dari hal ini 
peneliti menilai bahwa Ustadz Haikal Hassan memiliki eunia, bahwa bukan hanya perduli untuk dirinya sendiri melainkan juga untuk kepentingan umat.

Menurut Aristoteles jika seorang sudah mempunyai eunia ketika di atas, maka seorang orator atau pembicara adalah orator yang berethos yang dapat di percaya oleh public. Dengan begitu peneliti menyimpulkan bahwa Ustadz Haikal Hassan adalah seorang orator atau mublaig yang berethos. Kemudian di tinaju dari teortisnya, ethos bukanlah variable tunggal melaikan terdiri dari beberapa dimensi, yaitu :

Kredibilitas (merupakan presepsi dari pendengar kepada komnikator atas sikap dan sifat yang dilakukannya). Dalam hal ini saat peneliti menilai meliahat ceramah Ustadz Haikal Hassan di atas sudah menunjukan beliau memiliki kredibilitas yang ditinggi. Sebagai peneliti dan pendengar juga, peneliti merasa sikap yang di tunjukan saat bercramah sangatlah ramah, membuat nyaman, dan tidak memaksa untuk mengikuti pilihan beliau.

\section{Atraksi (daya tarik seorang komunikator yang dilihat dari fisik)}

Dalam bagian ini Ustadz Haikal Hassan memiliki daya tarik, jika dilihat secara fisik, Ustadz Haikal Hassan seperti campuran Arab-Indonesia, otomatis hidungnya akan bagus dan mancung, selalu berpakaian bersih.

Kekuasaan merupakan sikap yang ditimbulkan dari komunikator yaitu interkasi dengan para komunikan atau pendengar. Hal tersbeut yang menjadikan seornag komuniator mempunyai kehendak terhadap komunikannya. Hal ini bisa dilihat dari ceramah di atas saat Ustadz Haikal Hassan berkata " halus ye halus "

Phatos ini biasanya terlihat dari gaya bahasa yang di gunakan oleh komunikator yang mampu membangkitkan semangat komunikan. Karena seorang komunikator harus mampu perasaan, emosi, harapan, kebencian serta kasih sayang komunikan. Dalam buku rethorich Aristotels membahas bahwa phatos adalah persuasif pada pendengar . yang artinya seorang komunikator memang harus bisa menguasai perasaan komunikan.

Melihat dari ceramahnya di atas Ustadz Haikal Hassan sudah termasuk persuasif ajakannya yang halus kepada para jamaahnya agar memilih pemimpin muslim, dengan menginagtkan jamaahnya melalui hadits nabi bahwa kelak nanti orang itu akan di kumpulan dengan orang yang dicintai, dibela dan dipilihnya, jadi jika nanti ada yang memilih Ahok maha nanti akan di kumpulkan bersama Ahok

Dalam videonya Ustadz Haikal Hassan menyampaikanya dengan gaya yang santai, dan membuat para jamaahnya nyaman bahkan tertawa karena memang beliau selalu bisa membuat suasan menjadi cari. Phatos juga identik dengan rasa, menurut peneliti setelah melihat vidio tentang ini, membuat efek yang besar bagi peneliti untuk semakin yakin bahwa memilih pemimpin itu jangan hanya asal tanpa ada dalil yang kuat. 
Menurut Aristotels orator seharusnya memilik salah satunya adalah pengetahuan tentang fakta historis. Dalam ceramah Ustadz Haikal Hassan di atas menunjukan bahwa beliau memiliki kemampuan tentang fakta historis,di tunjukan dengan beliau hafal hadits nabi untuk memerkuat keyakinan pada jamaahnya. Dengan begitu bisa dikatakan bahwa Ustadz Haikal Hassan adalah orang yang memiliki sifat logos.

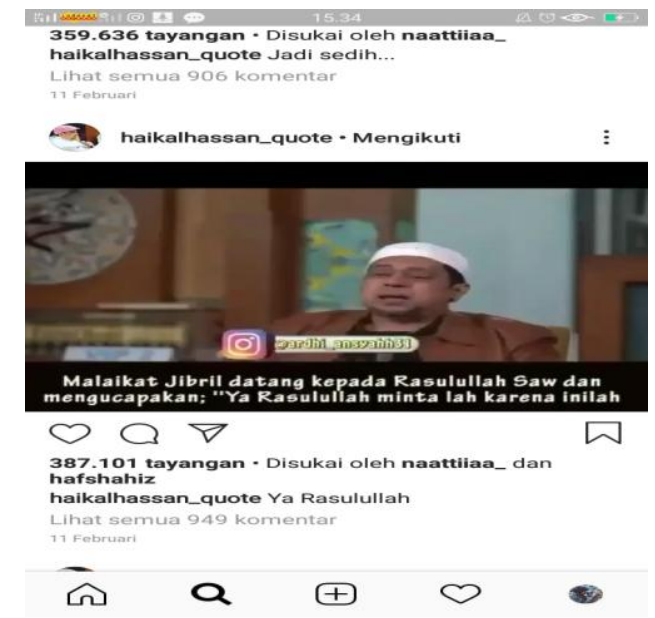

Gambar 2. Adegan tentang sikap logos ustadz Haikal Hassan

Seperti bahasan ethos dari ceramah ceramah sebelumnya, bahwa Ustadz Haikal Hassan adalh seseorang yang memiliki ethos, hal itu di buktikan dengan penelitian langsungg peneliti mendatangi kantor managementnya di Jakarta untuk meminta profil beliau. Dalam ceramah ini yang menunujukan Ustadz Haikal Hassan memiliki ethosdi lihat dari pengetahuan beliau tentang sejarah Indonesia juga sejarah Islam yang itu semua bukti bahwa Ustadz Haikal Hassan adalah seorang yang berethos. Dalam ceramah ini semua unsur ethos ada yaitu phraronesis, arete dan eunia.

Pharonesis adalah seorang komunikator bisa menentukan baik dan buruk atau lebih tepatnya bisa menetukan suatu perkara, dalam ceramah di atas Ustadz Haikal Hassan mengatakan bahwa jika UUD 1945 di gunakan dengan sebenar benarnya, maka rakyat Indonesia akan sejahtera. Pernyataan itu bisa masukk kedalam kategorisasi pharonesis.

Arete di lihat dari intelektualiatas dan karakter, yang berhubungan dengan pendidikan daan karekater bisa di lihat dari kegiatan yang di lakukan, seperti yang kita ketahaui Ustadz Haikal Hassan ini banyak sekali menjabat sebagai ketua di oragniasai, memenangkan menof the years 2018 dan banyak lagi, hal itu membuktikan bahwa Ustadz Haikal Hassan adalah sosok yang memeiliki karakter yang baik dan cerdas. 
Eunia dilihat dari kepedulian komunikator kepada semua orang tanpa terkecuali dalam ceramah di atas sudah menunjukan kepudulian Ustaadz Haikal Hassan memiliki eunia dalam dirinya,karena kepeduliannya terhadap masyarakat Indonesia

Phatos ini berhubungun dengan perasaan yang di rasak atau mad'u setelah mendengar ceramah dari mubaligh. Setelah meninton video di atas peneliti merasa lebih mencintai tanah air Inonesia ini dan berharap agar Indonesia akan menjadi negara yang maju dan penuh berkah. Cara penyampaian Ustadz Haikal Hassan yang penuh dengan semangat dan mengebu gebu dapat di rasakan juga oleh orang orang yang melihat videonya. Dengan begitu jelas bahwa Ustadz Haikal Hassan dalam ceramahnya kali ini memiliki unsur phatos.

Dilihat dari segi emosi dalam penyampian ceramah kali ini terlihat baik, Ustadz Haikal Hassan terlihat menggebu gebu saat yang menyampaikan ceramahnya, hingga pesan semangat itu terasa para mad'unya.

Seperti yang sudah peneliti bahas sebelumnya bahwa logos berhubungan dengan kemampuan seroang komunikator dalam pengetahuan historis , pengalaman dan pengetahuan lainnya yang harus bisa komunikator sampaikan menggunakan bahasa yang logis, agar komunikan atau mad'u dapat mengerti dengan mudah.

Dalam firman Allah dalam surat "Ad-Duha" Allah berfirman :

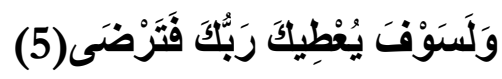

Artinya :"Dan kelak. Tuhanmu pasti memberikan karuniaNya kepadamu, lalu (hati) kamu menjadi puas.”( QS Ad-Duha : 5).

Malaikat Jibril pun gembira dengan ayat itu, malaikat Jibril datang kepada Rasulullahsaw dan mengucapkan :" ya Rasulullah minta lah karena inilah hari akan di berikan Allah apapun, "Apa ya Jibril", "sebut". Pengen kekuasaan "dapet pa hari itu pa" "tapi apa yang Rasulullah ucap"ketika di tawarkan "Walasanfa Yutbika Rabbuka Fatardaa" Rasulullah menjawab "kalau begitu ya Allah, tak kurela, satu saja umatku berada dalam api neraka”.

Saudaraku sekalian perbanyaklah solawat kepada nabi karena itu akan menumbuhkan tetesan-tetesan cinta kepada Rasulullah SAW. Di awali dengan menyebut nyebut bu pa sampai bergetar hati mu ketika di sebut nabi saw itu lah tanda cinta, ketika disebut nama ya Muhammad, ya Rasulullaah, getarkan hatimu karena itu lah tanda cinta yang sesungguhnya, dan tau kah bapa ibu sekalian apa sunnah nabi terbesar? Sunnah nabi terbesar adalah solat berjamaah di mesjid, dan kemudian yang wajib kita lakukan pesan nabi SAW adalah mencintai dan menghormati orang tua. Itu lah pahala di atas jihad bakti kepada orang tua di atas jihad. 
Dalam ceramah isi ceramah Ustadz Haikal Hassan kali ini, pembahasannya sangat jelas dan mudah di pahami, juga menunjukan bahwa Ustadz Haikal Hassan mempunyai pengetahuan historis yang luas. Menyampaikan dengan pemilihan kata dan kalimat yang tepat. Dengan demikian ceramah Ustadz Haikal Hassan memiliki unsur logos .

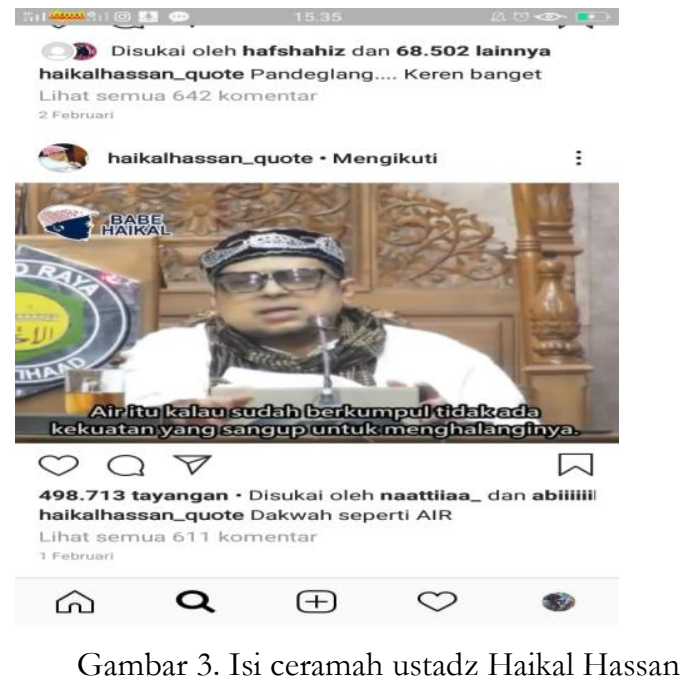

Ustadz Haikal Hassan memberikan contoh pada masa pemilu gubernur Jakarta, yang calon gubernurnya adalah Ahok dan Anis baswedan, disini jelas Ahok adalah non muslim sedangkan Anis adalah muslim, sangat jelas jika di lihat dari Al-Qur'an siapakah yang harus di pilih.

"hai orang orang yang beriman jangan lah kamu mengambil orang orang Yahudi dan Nasrani menjadi pemimpin pemimpin (mu); sebagaimana mereka adalah pemimpin bagi sebagian yang lain. Barangsiapa diantara kamu mengambil mereka sebagai pemimpin, maka sesungguhnya orang itu termasuk golongan mereka. Sesungguhnya Allah tidak memberi petunjuk pada orang orang yang zalim ”( QS. Al-Maidah :51).

Ustadz Haikal Hassan mengingatkan para mad'unya denga halus terlihat kemana tujuan dakwah dari Ustadz Haikal Hassan dalam dakwah ini yaitu salah satunya untuk membuat para jamaah sadar siapa yang harus mereka pilih untuk menjadi gubernur Jakarta selanjutnya.

Anis Baswedan pun menjadi gubernur di Jakarta, kepemipinannya saat ini bisa di bilang mencerminkan wajah Islam, dimana beliau mengajukan untuk menarik saham 1,2 triliun yang di simpan dalam alkohol, dan menyatakan bahwa orang Jakarta lebih membutuhkan air bersih dari pada air alkohol, selain itu juga Anis mengembalikan tanah kampung Aquarium yang sempat di gusur ketika Ahok memimpin. 
Dalam pidatonya Anis mengatakan bahwa "kita memang harus membrantas kemiskinan tapi tidak menghilangkan orang miskin". Karena memang tugas seorang da'i adalah untuk membentuk pemikiran menggiring opini kepada yang Allah Ridhai. (Tribun Jakarta.com. Selasa, 19 Maret 2019)

Ethos merupakan sebuah sikap atau suatu tindakan yang dilakukan oleh seorang komunikator yang akan meyakinkan kepada para pendengarnya bahwa dia adalah seorang yang ahli di bidang tersebut, sehingga akan membuat audience percaya dan yakin terhadap komunikator tersebut. (Unhjana, 1993 : $352)$.

Karena ketidakselaraan yang dilakukan oleh seorang mubaligh atau pembicara publik dari mulai perkataan hingga perbutaannya dinilai sangat tidak etis. Bahkan seharusnya seorang mubligh idealnya memounyai sifat -sifat nabi, yaitu jujur (shidiq), dapat di percaya (amanah), cerdas (fathanah), dan komunikatif (tabligh).

Dalam hal ini Ustadz Haikal Hassan adalah seorang komunikator atau mubaligh yang harus meyakinkan jamaah bahwa yang di sampaikan itu adalah benar. Wawasan yang di miliki Ustadz Haikal Hasaan pun luas sehingga para jamaah tidak ragu percaya atas apa yang di sampaikan beliau. Sebagaimana Ustadz Haikal Hassan selalu meyainkan jamaah bahwa yang di sampaikan itu sesuai dengan firma Allah dan hadits Rasulullaah. Seperti kutiipan ceramahnya berikut ini

Menurut Aristotels dalam buku zainul Maarif bawah ethos terdari dari: Phronesis yaitu mengetahui baik dan buruk. Dalam hal ini ustadz Haikal Hasaan bisa dikatakan sebagai seorang orator yang memiliki phronesis, seperti yang kita lihat pembahasan ceramah di atas dimana Ustadz Haikal Hassan menginagtkan untuk para jamaahnya agar memilih pemimpin yang beragama muslim, karena sudah jelas dalam Al- Quran Allah perintahkan. Hal itu menunjukan bahwa Ustadz Haikal Hassan bisa menentukan baik dan buruk dan bisa memutuskan suatu perkara mad'unya yaitu memberikan solusi siapa pemimpin yang harus di pilih. Jadi dalam hal peneliti bisa menyimulkan bahwa Ustadz Haikal Hassan memliki phronesis salah satu bagian dari ethos.

Saya mengibaratkan dakwah itu seperti air, dia menukik dan tidak bisa di bendung, mentok dengan batu dia akan mencari kiri kanan yang lain. Dan dakwah itu mesti fleksible seperti air di taro di gelas jadi bentuk gelas di taro di teko jadi bentuk teko, dakwah jelas tujuannya seperti mana air. Air pasti menuju tempat yang rendah, dan berkumpul disana itu lah dakwah. Dakwah ujungnya persatuan dan mengalir memberi manfaat kepada orang orang yang dibawah . dakwah itu seperti air, air itu kalau sudah berkumpul tidak ada kekuatan yang sanggup untuk menghalanginya. Dakwah kalau sudah berkumpul tidak ada kekuatan yang sanggup menghalanginya. Air di up, jadi uap naik turun kembali, 
air di panas kan naik di panaskan naik turun kembali, air tetep ada air itu adalah dakwah.

\section{PENUTUP}

Berdasarkan dari penelitian dalam analisis yang telah dilakukan penulis dalam meneliti retorika dakwah ustadz Haikal Hassan dalam media sosial Instragram @haikalhassan_quote. Maka peneliti menyimpulkan bahwa Ustadz Haikal Hassan yang biasa di panggil "Babeh " merupakan ustadz juga seorang kunsultan motivator juga seorang dosen yang awal mulanya di kenal sebabagi guru pengajaian anak anak dan remaja, kemudain mulai di kenal melalui aktifnya di media sosial Instagram hingga sekarang. Tidak hanya aktif di media sosial, ustadz Haikla Hassan juga sering mengisi pengajian di berbagai tempat bahkan kota dan juga sering diundang ke acara televisi.

Dari hasil pemaparan yang telah disampaikan, maka dapat ditarik kesimpulan sebagai berikut: pertama, Ethos pada penelitian ini, Ustadz Haikal Hassan adalah serorang yang berethos (apa yang di sampaikan dapat dipercaya oleh khalayak), dilihat dari ciri ciri ethos yaitu phoresis, arete dan eunia, Ustadz Haikal Hassan memilik ciri semuanya sebagai seorang ustadz. Dari enam video yang diteliti hasilnya adalah hampir semua video ceramah Ustadz Haikal Hassan memiliki unsur ethos di dalamnya. Hal ini menunukan bahwa teori aristoteles bahwa seroang $d a^{\prime} i$ komunikator memang harus mempunyai ethos agar apa yang di sampaikannya dapat diterima dengan mudah oleh para mad'unya. Kedua, Phatos adalah berhubungan dengan intonasi, pemilihan kata, dan nada saat berceramah, Selain itu unsur phatos yang lain adalah emosi dan karakter. Dari enam video yang di teleiti Ustadz Haikal Hassan mampu membuat emosi para mad'unya menjadi sedih, haru, bahkan semangat hal itu sudah pasti karena sosok Ustadz Haikal Hassan memiliki unsur phatos dalam dirinya. Ketiga, Logos seorang orator harus memiliki kemampuan historis, kemapuan analogi, kemampuan fiksi dan kemapuan untuk logis. Setelah melakukan penelitian dari video-video Ustadz Haikal Hassan di Instagram, peneliti menyimpulkan bahwa Usatdz Haikal Hassan memiliki semua ciri logos itu.

Adapun, dalam penelitian ini, ada beberapa saran yang telah peneliti sampaikan diantaranya yaitu: Untuk menambah keyakinan para jammaah kepada apa yang di sampaikan sebaiknya Ustadz Haikal Hassan juga mempelajari lagi lebih dalam tentang berbagi ilmu keagamaan atau ke Islaman. Karena melihat dari riwayat pendidikan beliau lebih banyak memepelajari tentang ilmu keduniaan. Ketika berdakwah mungkin tema yang di usung bukan hanya tentang keluarga namun juga untuk semua kalangan, karena banyak juga yang menyukai Ustadz Haikal Hassan ini di kalangan remaja dan dewasa. 


\section{DAFTAR PUSTAKA}

Abidin Yusuf, Zainal. 2018 Pengantar Retorika.Bandung : Pustaka Setia Arbi, Armawati. 2012.Psikologi Komunikasi Dan Tabligh. Jakarta : AMZAH Aziz Moh,Ali. 2015. Ilmu Dakwah.Jakarta : Pernadamedia Group. Enjang.2009, Dasar-Dasar Ilmu Dakwah. Widya Padjadjaran

Faudi M,H (2017). Pesan dakwah hasan albana dalam buku majmuat al-al-rasail, dalam ilmu dakwah : academic journal for 11 (2) 325-326. Homiletic studies.

Gulen, Fethullah. 2014.Dakwah.Jakarta : Republika Penerbit.

Ilaihi,Wahyu.2010. Komunikasi Dakwah. Bandunng : PT Remaja Rosdakarya

Keraf, Gorys. 2010. Diksi dan Gaya Bahasa. Jakarta : PT Gramedia Pustaka Utama.

Maarif, Zainul. 2015.Retorika Metode Komunikasi Publik. Jakarta : RajaGrafindo

Persada

Mulyana, Deddy. 2016. Ilmu Komunikasi.Bandung : PT Remaja Rosdakarya

Mulyana, Deddy. 2001 Human Communication.Bandung : PT Remaja Rosdakarya

Muhyiddin A. (2017), Retorika dakwah mamah dedeh dalam acara

"Mamah dan Aa Beraksi" di indosiar. Ilmu dakwah academic journal for homiletic studies, volume 11 No (2): 219-234, web 06 agustus 2019

Ridwan, A. 2009. Monologika; Retorika untuk Tabligh Islam Menelusuri sejarah menemukan arah) dalam Ilmu Dakwah: Academic Journal for Homiletic Studies, Vol. 4 No. 14. Juli-Desember 2009

Rakhmat, Jalaluddin.2012. Retorika Modern.Bandung : PT Remaja Rosdakarya

Suparta Munzier dan Hefni Harjani. 2015.Metode Dakwah.Jakarta : Prenadamedia Group

Suardi. 2017. Urgensi Retorika dalam Perspektif Islam dan Persepsi Masyarakat: Jurnal An-nida', Vol. 41 No. 2. Edisi Desember 2017 hal 132

Tajiri, Hajir. 2015. Etika dan Estetika Dakwah. Bandung : Simbiosa Rekatama Media 